\title{
O desenvolvimento regional sustentável e a interação dos atores locais na proposta do Geoparque Caminhos dos Cânions do Sul (SC/RS)
}

\section{The sustainable regional development and the interaction of local stakeholders in the proposal for the Geopark Caminhos dos Cânions do Sul (SC/RS, Brazil)}

\author{
Israel Vasconselos Cardoso, Joice Batista Felipe, \\ José Claudio Ramos Rodrigues
}

\begin{abstract}
RESUMO: A competitividade em ascensão no contexto de uma economia globalizada nos coloca diante do desafio de pensar estratégias diversas, incluindo as denominadas estratégias de não mercado na busca da mobilização e da participação ativa dos atores locais visando ao desenvolvimento regional sustentável. Nesse contexto o presente ensaio teórico, por meio de revisão bibliográfica e análise documental, se propõe a discutir a criação do Geoparque Caminhos dos Cânions do Sul e sua importância na promoção do desenvolvimento regional sustentável. A divulgação do Geoparque e seus geossítios tende a impulsionar e consolidar a região como destino turístico importante, fortalecendo o turismo (geoturismo) como principal atividade econômica para o desenvolvimento regional. No entanto, o presente estudo concluiu que para o sucesso do futuro Geoparque e as estratégias de desenvolvimento regional sustentável é imprescindível que haja um forte envolvimento e participação dos atores locais em todas as etapas desse processo.
\end{abstract}

PALAVRAS CHAVE: Geoparque Caminhos dos Cânions do Sul; Desenvolvimento Regional Sustentável; Estratégias de Não Mercado; Atores Locais.

ABSTRACT: The rise in the context of a globalized economy places us in the face of the challenge of thinking about diverse strategies including the so-called nonmarket strategies in the search for mobilization and the active participation of local actors aiming at sustainable regional development. Therefore, the present theoretical essay through bibliographical review and documentary analysis aims to discuss the creation of the Caminhos do Cânions do Sul Geopark and its importance in promoting sustainable regional development. The divulgation of the Geopark and its geosites tends to boost and consolidate the region as an important tourist destination, reinforcing tourism (geotourism) as the main economic activity for regional development. However, the present study concluded that it is essential for the success of the future Geopark and sustainable regional development strategies that there is a reinforce involvement and participation of local actors in all stages of this process.

KEYWORDS: Caminhos do Cânions do Sul Geopark; Sustainable Regional Development; Non-Market Strategies; Local Actors. 


\section{Introdução}

O Estado apresenta-se como principal ator do desenvolvimento de um país ou região até os dias atuais. Na busca da expansão do desenvolvimento do país e da sua economia, o incremento de investimentos públicos torna-se escasso. Desse modo, as organizações, sejam públicas, sejam privadas, buscam por meio de suas relações novos parceiros para investimentos que possam se aliar a fatores que promovam sua transformação nos setores produtivos, financeiros e políticos.

A competitividade continua em ascensão junto com o processo de globalização. As transformações dos setores, com a privatização de uns e a desregulamentação de outros, são fatores que contribuem para tal cenário.

Com o objetivo central de impulsionar o desenvolvimento e a competitividade de uma região, a formação de redes relacionais entre governo, firma e órgãos de apoio integra forças para identificação dos atores regionais no planejamento de uma agenda em comum (CASAROTTO FILHO; PIRES, 2001).

Para a sociedade o Estado tem o dever de garantir a ordem, o bemestar e a segurança diante de diferentes interesses que possam ocasionar situações de conflito. Oliveira (2001) afirma que o Estado tem como principal responsabilidade o controle de conflitos.

De acordo com Goulart et al. (2010), para que o sistema econômico possa apresentar uma forte estrutura no modelo voltado para as redes, o Estado tem papel fundamental como incentivador das instituições para garantir e estimular o desenvolvimento sustentável.

Algumas organizações têm forte participação do Estado em suas decisões (lobby). De um lado há o gestor da organização que participa do quadro de colaboradores do Estado; esse por sua vez não terá a necessidade de estabelecer uma nova estratégia relacional, podendo de tal maneira agregar valor à firma. De outro lado temos o gestor da organização que não possui e precisa estabelecer estratégias de mercado e não garantirá o mesmo tratamento.

Para Camilo (2011) a influência sobre a economia é de responsabilidade do governo diante das previsões de recursos financeiros por meio de políticas públicas, exercendo, desse modo, controle sobre as organizações, gerando a dependência e o domínio do Estado sobre toda a atividade econômica. Assim: "Um modelo assentado no uso de relações para explorar oportunidades de mercado ou para influenciar determinadas decisões de interesse" é definido como Capitalismo de Laço (LAZZARIN, 2011, p.3).

Um novo termo tem sido recentemente utilizado para entender como funcionam as estratégias e alianças políticas na economia brasileira. Tratase das "estratégias de não mercado", denominadas também estratégias de política empresarial.

Relatos de Qian (2010) apresentam o crescimento sobre a concepção e implementação de estratégia de não mercado, que por sua vez 
tem atraído a atenção não só dos mercados desenvolvidos, mas também de economias emergentes.

As estratégias de mercado têm sua representatividade e suas definições mais conceituadas. Já as ações designadas a motivar os atores em questões institucionais voltadas à política pública são definidas como estratégias de não mercado. Tais estratégias têm como propósito a coletividade de ações de forma mais abrangente frente à estratégia de mercado.

Nesse contexto, abordaremos a implementação do Geoparque Caminhos dos Cânions do Sul (SC/RS), que tem potencial para alavancar economicamente a região e promover o desenvolvimento regional sustentável, por meio do geoturismo, a partir do envolvimento dos atores locais.

A descoberta da importância do geoturismo e da geoconservação no Brasil é bastante recente, revelando-se um longo caminho pela frente em direção à sistematização do seu conhecimento para o desenvolvimento de novas estratégias.

A proposta da criação de um programa de geoparques por parte da UNESCO surgiu em Digne, na França, em 1991, no evento que instituiu a Declaração Internacional dos Direitos da Memória da Terra.

Para Souza, Pena e Moesch (2017), as políticas públicas devem ser iniciadas com o propósito de estruturar uma rede de governança. Assim, este artigo objetiva identificar as questões teóricas centrais presentes no debate dos estudos sobre estratégia de não mercado e desenvolvimento regional sustentável, por meio de revisão bibliográfica e análise documental da proposta de efetivação do Geoparque Caminhos dos Cânions do Sul.

\section{O projeto Geoparque Caminhos dos Cânions do Sul (SC/RS)}

É importante trazermos algumas informações para contextualizar o tema Geoparque antes de abordar o Projeto do Geoparque Caminhos dos Cânions do Sul especificamente. Destarte, serão apresentados a seguir os conceitos sobre a construção e a formulação de um geoparque, seus objetivos, uma breve caracterização e, por fim, a proposta do Geoparque Caminhos dos Cânions do Sul, em Santa Catarina e no Rio Grande do Sul.

O termo "geoparque" é atribuído pela Rede Global de Geoparques, sob os auspícios da UNESCO, a uma área em que sítios do patrimônio geológico representam parte de um conceito holístico de proteção, educação e desenvolvimento sustentável (CPRM, 2019a).

Podemos definir geoparque como um território com limites bem definidos e que apresenta um rico patrimônio geológico de importância internacional, nacional e/ou regional, articulado com uma estratégia de desenvolvimento sustentável. Trata-se de uma área que integra diversos geossítios, que são locais de interesse geológico de especial valor científico, mas também educativo e/ou turístico. Além dos aspectos geológicos relevantes, a presença de valores ecológicos, históricos ou culturais 
permitem a realização de projetos educacionais e/ou turísticos (FARSANI; COELHO; COSTA, 2010).

Ainda segundo definição da UNESCO (2006) um geoparque é uma região com limites bem definidos, envolvendo um número de sítios do patrimônio geológico-paleontológico de especial importância científica, raridade ou beleza, não apenas por razões geológicas, mas também por seu valor arqueológico, ecológico, histórico ou cultural. deve:

Em síntese, um geoparque, de acordo com o conceito da UNESCO,

-Preservar o patrimônio geológico para futuras gerações (geoconservação).

-Educar e ensinar o grande público sobre temas geológicos e ambientais e prover meios de pesquisa para as geociências.

-Assegurar o desenvolvimento sustentável através do geoturismo, reforçando a identificação da população com sua região, promovendo o respeito ao meio ambiente e estimulando a atividade socioeconômica com a criação de empreendimentos locais, pequenos negócios, indústrias de hospedagem e novos empregos.

-Gerar novas fontes de renda para a população local e a atrair capital privado (CPRM, 2019b, p.1).

Em 13 de fevereiro de 2004 foi criada a Rede Global de Geoparques Nacionais, comumente referida como Rede Global de Geoparques (Global Geoparks Network - GGN) em reunião realizada na sede da UNESCO, em Paris. Participaram dessa reunião os membros do Conselho Científico do Programa Internacional de Geociências (International Geoscience Programme - IGCP), representantes da União Geográfica Internacional (International Geographical Union - IGU) e da União Internacional das Ciências Geológicas (International Union of Geological Sciences - IUGS), além de especialistas internacionais sobre a conservação e promoção do patrimônio geológico.

Para candidatar-se à rede, o aspirante a geoparque da RGG deve submeter documento ou dossiê de candidatura (application dossier) à Divisão de Ciências Ecológicas e da Terra (Division of Ecological and Earth Sciences) da Unesco (CPRM, 2019b).

No Brasil, o Projeto Geoparques, criado pelo Serviço Geológico do Brasil (CPRM) em 2006, tem um papel indutor importante na criação de geoparques no país, uma vez que tal projeto tem como premissa básica a identificação, levantamento, descrição, inventário, diagnóstico e ampla divulgação de áreas com potencial para futuros geoparques no território brasileiro (CPRM, 2019b).

Cabe destacar que no Brasil existe um único geoparque, denominado Geopark Araripe, criado em 2006 e localizado na Bacia do Araripe, ao sul do estado do Ceará, abrangendo seis municípios em uma área de aproximadamente $3.441,42 \mathrm{~km}^{2}$ (UNESCO, 2019). 
O Projeto Geoparque Caminhos dos Cânions do Sul nasceu por iniciativa do Dr. João Matos, então prefeito do município de Praia Grande (2005-2008), que idealizou o desenvolvimento da região com base no turismo, considerando as belezas naturais das escarpas da Serra Geral (SANTA CATARINA, 2018). De acordo com Rosa (2016), a proposta surgiu em 2007 com o início das discussões sobre a possibilidade do Geoturismo como uma estratégia para o desenvolvimento regional.

Geoturismo pode ser definido como a disponibilização de serviços e meios interpretativos que promovem a valorização e trazem benefícios sociais a lugares com atrativos geológicos e geomorfológicos, garantindo sua conservação, para o uso de estudantes, turistas e demais pessoas com interesses recreativos (HOSE, 2000).

A partir de 2009 a Secretaria de Desenvolvimento Regional de Araranguá (SDR) assumiu as ideias vindas de Praia Grande e passou a liderar "[...] ações iniciais que envolveram sensibilização, articulação local e apresentação da intenção da candidatura da região a organismos competentes nas esferas nacional e internacional' (RELATÓRIO FOTOGRÁFICO 2009, 2018, p.4). Ainda segundo o mesmo documento, a partir de 2010 foi efetivada uma parceria com a Associação dos Municípios de Extremo Sul Catarinense (AMESC), em que foram deflagradas novas ações para a construção coletiva do projeto em conformidade com as diretrizes expressas em documentos da UNESCO.

Segundo o documento Relatório das Ações (SANTA CATARINA, 2018), essa parceria da SDR de Araranguá com a AMESC se estendeu até 2017, quando foi criado o Consórcio Público Intermunicipal Caminhos dos Cânions do Sul, composto pelos sete municípios que atualmente compõem a proposta, passando a assumir a coordenação do projeto.

Alguns dados relevantes sobre o Projeto Geoparque Caminhos dos Cânions do Sul são apresentados no documento Relatório Fotográfico Anexo 1 (SANTA CATARINA, 2018), ao afirmar que o projeto

[...] trata da preparação do território, atualmente composto pelos municípios catarinenses de Praia Grande, Jacinto Machado, Timbé do Sul e Morro Grande e os gaúchos Cambará do Sul, Mampituba e Torres, para a submissão de candidatura no Programa Geoparques Mundiais da UNESCO. O território abrange área de $2.830 \mathrm{~km}^{2}$ e possui população de 73.347 pessoas (SANTA CATARINA, 2018, p.4).

A Figura 1 apresenta a localização e a área candidata ao Geoparque Caminhos dos Cânions do Sul, a partir de 2015. 


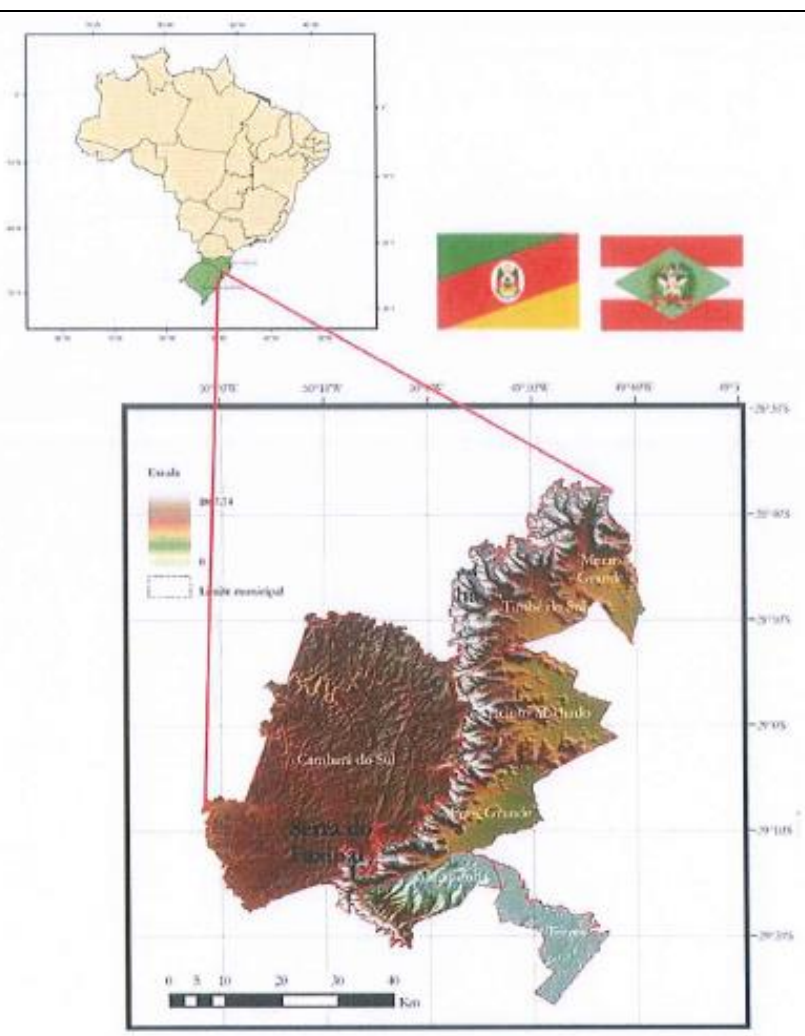

Figura 1: Área candidata ao Geoparque Caminhos dos Cânions do Sul.

Figure 1: Prospective area for the Geopark Caminhos dos Cânions do Sul.

Fonte: Adaptado de Schobbenhaus e Silva (2012) apud Relatório das Ações (2018).

Source: Adapted from Schobbenhaus and Silva (2012) apud Actions Report (2018).

O Quadro 1, a seguir, apresenta uma relação com os treze geossítios inventariados pelo Serviço Geológico do Brasil (CPRM), nos sete municípios que compõem a área candidata ao Geoparque Caminho dos Cânions do Sul.

Quadro 1: Geossítios inventariados no Projeto Geoparque Caminhos dos Cânions do Sul.

Table 1: Inventoried geosites in the Project Geopark Caminhos dos Cânions do Sul.

\begin{tabular}{|c|c|c|c|}
\hline GEOSSÍTIO & MUNICÍPIO & RELEVÂNCIA & POSSÍVEL UTILIZAÇÃO \\
\hline $\begin{array}{c}\text { Furnas dos Índios } \\
\text { Xocleng }\end{array}$ & $\begin{array}{l}\text { Jacinto } \\
\text { Machado }\end{array}$ & Regional & $\begin{array}{c}\text { Turística/recreativa, } \\
\text { científica, pedagógica, } \\
\text { histórica/cultural }\end{array}$ \\
\hline Morro Carasal & $\begin{array}{l}\text { Jacinto } \\
\text { Machado }\end{array}$ & Regional & $\begin{array}{c}\text { Científica, } \\
\text { turística/recreativa }\end{array}$ \\
\hline Cânion da Pedra & $\begin{array}{l}\text { Jacinto } \\
\text { Machado }\end{array}$ & Regional & $\begin{array}{l}\text { Científica, } \\
\text { turística/recreativa- } \\
\text { pedagógica }\end{array}$ \\
\hline Morro da Moça & $\begin{array}{l}\text { Jacinto } \\
\text { Machado }\end{array}$ & Regional & $\begin{array}{l}\text { Turística/recreativa, } \\
\text { histórica/cultural }\end{array}$ \\
\hline $\begin{array}{l}\text { Parque da } \\
\text { Guarita }\end{array}$ & Torres & Internacional & $\begin{array}{c}\text { Científica, } \\
\text { turística/recreativa, } \\
\text { pedagógica, } \\
\text { histórica/cultural }\end{array}$ \\
\hline
\end{tabular}

Continua... 


\begin{tabular}{|c|c|c|c|}
\hline GEOSSÍTIO & MUNICÍPIO & RELEVÂNCIA & POSSÍVEL UTILIZACÃO \\
\hline Pedra Branca & Mampituba & Regional & $\begin{array}{l}\text { Turística/recreativa, } \\
\text { histórica/cultural }\end{array}$ \\
\hline Cânion Fortaleza & $\begin{array}{l}\text { Cambará do } \\
\text { Sul/ Jacinto } \\
\text { Machado }\end{array}$ & Internacional & $\begin{array}{l}\text { Turística/recreativa, } \\
\text { científica, pedagógica, } \\
\text { histórica/cultural }\end{array}$ \\
\hline $\begin{array}{c}\text { Cânion } \\
\text { Itaimbezinho }\end{array}$ & $\begin{array}{l}\text { Praia Grande/ } \\
\text { Cambará do Sul }\end{array}$ & Internacional & $\begin{array}{c}\text { Turística/recreativa, } \\
\text { científica, pedagógica, } \\
\text { histórica/cultural }\end{array}$ \\
\hline $\begin{array}{l}\text { Cânion Monte } \\
\text { Negro }\end{array}$ & $\begin{array}{l}\text { Morro Grande/ } \\
\text { São José dos } \\
\text { Ausentes }\end{array}$ & Regional & $\begin{array}{c}\text { Turística/recreativa, } \\
\text { científica }\end{array}$ \\
\hline $\begin{array}{l}\text { Mirante Timbé do } \\
\text { Sul }\end{array}$ & Timbé do Sul & Regional & $\begin{array}{l}\text { Turística/recreativa, } \\
\text { científica, pedagógica }\end{array}$ \\
\hline $\begin{array}{l}\text { Pedra do } \\
\text { Segredo }\end{array}$ & $\begin{array}{c}\text { Jacinto } \\
\text { Machado/ } \\
\text { Cambará do Sul }\end{array}$ & Internacional & $\begin{array}{l}\text { Turística/recreativa, } \\
\text { científica, pedagógica }\end{array}$ \\
\hline Cânion Malacara & $\begin{array}{l}\text { Praia Grande/ } \\
\text { Cambará do Sul }\end{array}$ & Internacional & $\begin{array}{l}\text { Turística/recreativa, } \\
\text { científica, pedagógica }\end{array}$ \\
\hline $\begin{array}{l}\text { Ácidas de } \\
\text { Cambará }\end{array}$ & Cambará do Sul & Regional & Científica/pedagógica \\
\hline
\end{tabular}

O objetivo geral do Projeto Geoparque Caminhos dos Cânions do Sul no período de parceria entre a SRD de Araranguá e a AMESC foi focado em "[...] implementar governança local para construção coletiva do projeto geoparque com vistas a atender quesitos estabelecidos pela UNESCO e Rede Global de Geoparques" (SANTA CATARINA, 2018, p.3).

\section{O Projeto Geoparque Caminhos dos Cânions do Sul (SC/RS) e o desenvolvimento regional sustentável}

Em nenhum outro momento da história percebemos a humanidade tão envolvida com a temática da conservação da natureza e do desenvolvimento sustentável como nos tempos atuais. A conservação da biodiversidade e da geodiversidade, que se encontram ameaçadas por fatores distintos, é um aspecto importante e necessário para a promoção de um desenvolvimento regional sustentável. A geodiversidade é um conceito análogo à biodiversidade, porém não tem conquistado o mesmo grau de reconhecimento na sociedade e refere-se à diversidade geológica (BRILHA, 2005).

A origem do termo "desenvolvimento sustentável" não é consensual, mas segundo alguns autores teria surgido com 0 nome de ecodesenvolvimento. Com relação a essa polêmica, Sachs (2009, p.54) observa: "Quer seja denominado ecodesenvolvimento ou desenvolvimento sustentável, a abordagem fundamentada na harmonização de objetivos sociais, ambientais e econômicos não se alterou desde o encontro de Estocolmo [...]". 
Muitos autores afirmam que a origem e o processo de evolução histórica da concepção de desenvolvimento sustentável se deram a partir da preocupação com a problemática ambiental iniciada nas décadas de 1960 e 1970 (RODRIGUES, 2017). Ainda segundo o autor, entre os muitos eventos que contribuíram para a construção da ideia do desenvolvimento sustentável, ocorridos sobretudo na década de 1970,

A Conferência de Estocolmo, realizada em 1972, foi considerada um marco no debate ambiental em nível internacional. Pela primeira vez discutiam-se formas de conciliar a proteção ambiental ao crescimento econômico, com a participação dos países desenvolvidos, que se mostraram interessados em buscar soluções para a crescente degradação ambiental (RODRIGUES, 2017, p.46).

O economista Ignacy Sachs, que teve participação ativa no processo de construção histórica do que mais tarde viria a se chamar desenvolvimento sustentável, formulou os princípios dessa nova visão do desenvolvimento propondo: (i) satisfação das necessidades básicas; (ii) solidariedade com as gerações futuras; (iii) participação da população; (iv) proteção dos recursos naturais; (v) elaboração de um sistema social, com garantia de emprego, renda, segurança e respeito às culturas locais; e (vi) programas de Educação (SACHS, 1981).

O termo "desenvolvimento sustentável" e seus fundamentos somente vão aparecer claramente no relatório "Nosso Futuro Comum" (Our Common Future), da Comissão Mundial sobre Meio Ambiente e Desenvolvimento. No relatório, o desenvolvimento sustentável é definido como aquele que atende às necessidades das gerações atuais sem comprometer a capacidade das gerações futuras de atender às suas necessidades e aspirações. Embora existam outros conceitos e interpretações sobre o desenvolvimento sustentável, a definição expressa nesse relatório se tornou clássica e, por essa razão, acabou se impondo como padrão em quase toda a literatura que aborda a conceituação ou a definição de desenvolvimento sustentável.

Conforme o documento da UNESCO intitulado Guidelines and Criteria for National Geoparks seeking UNESCO's assistance to join the Global Geoparks Network (GGN), de 2010, um geoparque deve contar com forte apoio da comunidade e envolvimento local e ser desenvolvido a partir de um processo de base. Deve contar ainda com o apoio de políticos e lideranças das comunidades locais, inclusive no que se refere a recursos financeiros necessários (UNESCO, 2010).

Ainda segundo o documento, o geoparque precisa contar também com uma estrutura de gerenciamento eficaz e profissional e definir políticas e ações para o desenvolvimento regional sustentável nas esferas social, econômica e cultural de forma a contemplar todo o território do geoparque. $O$ sucesso do geoparque só será alcançado por meio de um forte envolvimento 
local. Portanto, a iniciativa de criar um geoparque deve partir de lideranças e comunidades que tenham compromisso com o desenvolvimento e a implementação de um plano de gestão que atenda às necessidades sociais e econômicas da população local.

Reforçando a importância do envolvimento e a participação direta da comunidade local, o documento da UNESCO intitulado UNESCO Global Geoparks: celebrating earth heritage, sustaining local communities de 2016 acrescenta:

\begin{abstract}
Geoparques Mundiais da UNESCO visam o empoderamento das comunidades locais e proporcionam oportunidades de desenvolver sólidas parcerias [...] são criados por meio de processos desenvolvidos de baixo para cima (bottom-up), envolvendo segmentos sociais interessados (por exemplo, proprietários de terras, grupos da comunidade, trade turístico, população indígena e entidades locais) e autoridades locais e regionais relevantes (UNESCO, 2016).
\end{abstract}

Um dos quatro elementos essenciais de um geoparque mundial da UNESCO é a gestão do território. Assim, o desenvolvimento regional sustentável deve ser concebido, planejado e executado por uma entidade gestora legalmente reconhecida com base na legislação nacional. Essa entidade deve ser devidamente capaz de fazer a gestão de todo o território e deve incluir todos as autoridades e atores locais e regionais relevantes (UNESCO, 2016). No caso do geoparque aspirante Caminhos dos Cânions do Sul, a entidade gestora é desde 2018 o Consórcio Público Intermunicipal Caminhos dos Cânions do Sul.

Conforme já abordado neste artigo, um dos objetivos de um geoparque de acordo com a UNESCO é promover o desenvolvimento sustentável por meio do geoturismo. O turismo ou geoturismo sustentável e outras atividades econômicas dentro de um geoparque, conforme já destacado anteriormente, só serão bem-sucedidos se realizados em cooperação com as comunidades locais (UNESCO, 2010).

A atividade turística é bastante desenvolvida na região de abrangência do futuro Geoparque Caminhos dos Cânions do Sul, especialmente nos municípios de Praia Grande, Jacinto Machado e Cambará do Sul, em razão dos Parques Nacionais Aparados da Serra e Serra Geral, onde se encontram os cânions, e o município de Torres devido ao Parque Estadual da Guarita.

O Parque Nacional de Aparados da Serra foi criado através do Decreto n. 47.446, de 17 de dezembro de 1959, com uma área estimada de 13.000 ha $\left(130 \mathrm{~km}^{2}\right)$, somente em terras do planalto gaúcho. Foi ampliado para o território catarinense em 17 de março de 1972 por meio do Decreto $\mathrm{n}$. 70.296. Mesmo se tratando de uma ampliação, a área citada no decreto é aproximada, com um total de 10.250 ha $\left(102 \mathrm{~km}^{2}\right)$ (ICMBIO, 2019a). Já o Parque Nacional (Parna) da Serra Geral foi criado pelo Decreto n. 531, de 20 de maio de 1992, com área de 17.300 ha. (ICMBIO, 2019b). Por fim, o 
Parque Estadual da Guarita teve seu início com a promulgação do Decreto Estadual 21.540, de 28 de dezembro de 1971 (PREFEITURA DE TORRES, 2019).

São bastante conhecidos e facilmente encontrados na literatura os impactos positivos que a atividade turística pode trazer às comunidades locais. Ela movimenta e beneficia diversos setores, como o de hospedagem, alimentação, transporte, indústria e comércio em geral. De forma indireta também traz benefícios aos agricultores, artistas e artesãos locais, por exemplo fortalecendo a identidade e a cultural local e regional e contribuindo para a melhoria da qualidade de vida das pessoas.

Por outro lado, também são conhecidos os impactos negativos que a atividade turística pode gerar quando mal planejada, especialmente quanto à conservação dos recursos naturais. Dessa forma é igualmente importante o desenvolvimento de estratégias e ações para assegurar a conservação e proteção dos geossítios, que são os grandes atrativos turísticos do futuro geoparque.

Para além da atividade turística já consolidada nos parques mencionados, é importante pensar estratégias que busquem promover a integração da atividade turística junto aos sete municípios que compõem o atual território do futuro geoparque. É necessário que a entidade gestora do geoparque aspirante busque construir, de forma coletiva e participativa, um plano de gestão para o turismo que promova o fortalecimento dos destinos já estabelecidos e beneficie o desenvolvimento regional de forma sustentável.

O turismo deve de ser especialmente concebido para se adequar às condições locais e às características naturais e culturais do território e devem respeitar totalmente as tradições da população local. O compromisso com o respeito, a proteção e a promoção dos valores culturais locais é um aspecto fundamental do esforço para o desenvolvimento sustentável (UNESCO, 2010).

\section{Desenvolvimento regional e estratégias de não mercado: um elo fortalecedor para o capital social por meio do Geoparque Caminhos dos Cânions do Sul}

Com a intensificação da competitividade e o aumento da globalização, tornaram-se necessários a reestruturação e o aprimoramento na gestão e suas estratégias no intuito de garantir a sobrevivência e a inovação nos relacionamentos de redes. Para que se obtenha sucesso na formação de redes, o sistema econômico local deve ser estruturado e contar com a participação efetiva de todos os atores.

Para Goulart et al. (2010), o sistema econômico estruturado no modelo de redes deve ter a participação do Estado como incentivador e promotor de mecanismos associativos para estimular o desenvolvimento sustentável.

Ao trazermos à tona o termo desenvolvimento regional, podemos vincular questões econômicas, políticas e sociais, o que resulta em uma visão ampla do termo. 
Diante desse contexto, o conceito de desenvolvimento regional não está relacionado apenas ao fortalecimento dos atores com potencialidades voltadas a uma melhora na qualidade de vida, mas a sua participação local como um instrumento que possibilita um desenvolvimento equilibrado, além de promover um processo democrático para a sociedade.

Segundo Goulart et al. (2010), o processo de globalização econômica regional tem como base as articulações dos atores, não somente na esfera econômica, como também na social, ambiental, política e cultural.

Diante da proposição de desenvolvimento e participação social, o Geoparque Caminhos dos Cânions do Sul tem como um dos objetivos a inserção dos atores locais em suas atividades, inserindo-os no contexto para promoção do desenvolvimento social e regional, a fim de que a proposta seja aceita no âmbito do Programa da Unesco (Global Geoparks).

A estratégia de mercado em sua generalidade tem suas interações voltadas diretamente com interesses do próprio mercado; já a estratégia de não mercado integra as ações dos atores institucionais, influenciando-os a determinar as estratégias de políticas públicas, representando um coletivo de ações.

A importância da investigação deste estudo é enfatizada por Baron (2001), ao evidenciar que a estratégia de não mercado pode ser um fator importante no desenho da estratégia geral dos negócios.

Um dos caminhos para o sucesso gerencial é a influência das estratégicas políticas no processo de política pública. Diante disso, Qian (2010) compreende que a intenção para o desenvolvimento de uma estratégia de não mercado tem em seu desígnio esforços para a redução das incertezas geradas pelo mercado. Desse modo, minimizam-se os efeitos da regulamentação e aumentam as oportunidades com o Estado.

Tal contexto torna-se de suma importância sobre a compreensão da estratégia de não mercado na implementação de um geoparque. Relacionam-se os avanços com a proposta e os desafios de implantação e a manutenção do parque. Outro fator preponderante para a estratégia de não mercado é destacado em três categorias: desempenho, tomada de decisão, contexto e ambiente regulado. Diante de tais categorias o desempenho apresenta-se mais efetivo e facilita a influência na tomada de decisões.

As diferentes dinâmicas que um geoparque proporciona devem ser vistas como a criação de um ambiente capaz de promover e apoiar 0 desenvolvimento sustentável, econômico e social por meio do geoturismo. A utilização de ferramentas da administração regional para o gerenciamento dos recursos do geoparque pode trazer valiosas contribuições a partir de um caráter multidisciplinar que permite uma visão mais holística e integrada do meio.

Desse modo é importante que haja flexibilidade gerencial para moldar as estratégias, de modo a permitir uma melhor adequação do planejamento com a realidade local, além de articular os atores em grupos de trabalhos mais condizentes com os objetivos do território. 


\section{Considerações finais}

Com base na análise documental foi possível evidenciar que a Secretaria de Desenvolvimento Regional de Araranguá tem papel relevante no que diz respeito aos encaminhamentos das necessidades dos municípios, atuando como elo junto ao Estado e empenhando-se na busca de recursos e parcerias com o intuito de suprir as necessidades do projeto e buscar a valorização da região.

A formulação de uma política pública é necessária como um instrumento norteador das decisões e ações do Estado, pois o objetivo é a obtenção do interesse coletivo. Para que o Estado regule o interesse em virtude da coletividade, a articulação de diretrizes nos diversos setores é fundamental.

É notório que o desenvolvimento e a melhoria da competitividade regional sustentável se dão pela interação eficiente na formação de redes entre os atores que participam do processo. A diligência pela conscientização dos atores deve ser um processo contínuo, principalmente para os órgãos públicos, buscando atingir os benefícios da formação de redes regionais.

Um dos efeitos econômicos com características mais impactantes que resultam na formulação de políticas públicas é o turismo, pois torna-se um instrumento regulatório.

O projeto Geoparque Caminhos dos Cânions do Sul cria uma importante dinâmica ao possibilitar uma nova forma de gestão territorial, em que elementos do patrimônio geológico, a cultura, a história, a gastronomia e o turismo são desenvolvidos a partir de ações participativas que integram os diversos atores junto à população local.

O processo participativo torna-se um meio de construção de conhecimento desses atores sociais. O projeto permite a inserção da comunidade em suas ações e a população é estimulada a exercer seu poder participativo no processo de construção das ações no âmbito do geoparque.

Diante desse contexto, pode-se afirmar que o geoparque já traz uma grande contribuição para a construção de um processo participativo já em curso, podendo evoluir para a formação de redes que permitam uma maior interação e protagonismo dos atores sociais.

Como sugestão para futuras pesquisas recomenda-se adaptar e replicar o modelo utilizado para avaliar e entender $o$ modelo e a diferenciação no âmbito de formação de redes, além de possibilitar comparativos entre as agências.

Destaca-se a importância de refazer a pesquisa após a conquista do selo de Geoparque junto à UNESCO para avaliar as melhorias geradas no processo de formação de redes e no desenvolvimento regional. 


\section{Referências}

BARON, D. Private politics, corporate social responsibility, and integrated strategy. Journal of Economics and Management Strategy, [s. I.], v. 10, n. 1, p. 7-45, Spring 2001.

BRILHA, J. Patrimônio geológico e geoconservação: a conservação da natureza na sua vertente geológica. Viseu, Portugal: Palimage, 2005.

CAMILO, S. P. O. Conexões políticas e desempenho das empresas listadas na BM\&FBovespa: análise sob a ótica da governança e da dependência de recursos. 2011. Tese (Doutorado em Administração e Turismo) - Univali, Biguaçu-SC, 2011. $223 \mathrm{p}$.

CASAROTTO FILHO, N.; PIRES, L. H. Redes de pequenas e médias empresas e desenvolvimento local: estratégias para a conquista da competitividade global com base na experiência italiana. São Paulo: Atlas, 2001.

CPRM. Serviço Geológico do Brasil. Geoparque Caminhos dos Cânions do Sul (RS/SC) - proposta. Porto Alegre: CPRM, 2011. 36 p. Disponível em: $\quad<$ http://rigeo.cprm.gov.br/xmlui/bitstream/handle/doc/17168/ canionsdosul.pdf?sequence $=1>$. Acesso em: 3 jan. 2019.

CPRM. Serviço Geológico do Brasil. Projeto Geoparques. Porto Alegre, CPRM [s. I.]. Disponível em: <http://www.cprm.gov.br/publique/GestaoTerritorial/Gestao-Territorial/Saiba-Mais---Projeto-Geoparques-5415.html>.

Acesso em: 3 jan. 2019.

GOMES, C. S. C. D.; AZEVEDO, F. F. de. Um olhar no Geoparque Seridó à luz do desenvolvimento e do capital social. Caderno Virtual de Turismo. Rio de Janeiro, v. 18, n. 1, p. 116-132, abr. 2018.

GOULART, S. et al. Articulações em rede e acontecimentos no território: subsídios teóricos para a formação de políticas públicas para 0 desenvolvimento. Cadernos EBAPE.BR (FGV), v. 8, n. 3, p. 388-403, 2010.

HOSE, T.A. "Geoturismo" europeo. Interpretación geológica y promoción de La conservación geológica para turistas. In: BARRETINO, D.; WIMBLEDON, W.A.P.; GALLEGO, E. (Eds.). Patrimonio geológico: conservación y gestión. Instituto Tecnológico Geominero de España, Madrid, 2000. p. 137159.

ICMBIO. Instituto Chico Mendes de Conservação da Biodiversidade. Ministério do Meio Ambiente. Parque Nacional de Aparados da Serra. Brasília, 2019. Disponível em: <http://www.icmbio.gov.br/ parnaaparadosdaserra/>. Acesso em: 4 jan. 2019a.

ICMBIO. Instituto Chico Mendes de Conservação da Biodiversidade. Ministério do Meio Ambiente. Parque Nacional da Serra Geral. Brasília, 2019. Disponível em: <http://www.icmbio.gov.br/portal/visitacao1/unidadesabertas-a-visitacao/730-parque-nacional-da-serra-geral.html>. Acesso em: 4 jan. 2019b.

LAZZARINI, S. G. Capitalismo de laços: os donos do Brasil e suas conexões. Rio de Janeiro: Elsevier, 2011. 
OLIVEIRA, F. O. Política e Estado no Pensamento Marxista. 2001. Disponível em: <https://periodicos.ufsc.br/index.php/sequencia/ article/view/15363/13945>. Acesso em: 22 dez. 2018.

QIAN, C. Seize the state, seize the day? Business-government relations in a transition economy. Hong Kong: Hong Kong University of Science and Technology, 2010.

RODRIGUES, J. C. R. A educação ambiental no ensino médio: uma proposta teórico-metodológica no contexto da diversidade como princípio formativo na atualização da proposta curricular de Santa Catarina. Tese (Doutorado- Programa de Pós-Graduação em Geografia da Universidade Federal de Santa Catarina, UFSC), Florianópolis, 2017. 519 p.

ROSA, T. R. da. Das unidades de conservação ao projeto geoparque caminhos dos canyons do sul (SC/RS). Dissertação (Mestrado Profissional Programa de Pós-Graduação em Planejamento Territorial e Desenvolvimento Socioambiental da Universidade do Estado de Santa Catarina, UDESC), Florianópolis, 2016. 150 p.

SACHS, I. Ecodesenvolvimento: crescer sem destruir. São Paulo: Vértice, 1981.

SACHS, I.; STROH, P. Y. (Org.). Caminhos para o desenvolvimento sustentável. Rio de Janeiro: Garamond, 2009.

SANTA CATARINA. Relatório Fotográfico 2009-2018. Anexo 1. Disponível em: $\quad<h t$ tps://sgpe.sea.sc.gov.br/atendimento/visualizarDocumentosPDF Processo.do?chaveProcesso=MTM1NzBfMjAxOF82NjYxLTE\%3D>. Acesso em: 26 dez. 2018.

SANTA CATARINA. Relatório das Ações Desenvolvidas no Projeto Geoparque Caminhos Dos Cânions Do Sul. Governo de Santa Catarina, 2019. Disponível em: <https://sgpe.sea.sc.gov.br/atendimento/ visualizarDocumentosPDFProcesso.do?chaveProcesso=MTM1NzBfMjAxOF 82NjYxLTE\%3D>. Acesso em: 26 dez. 2018.

SOUZA, L. H.; PENA, L. C. S.; MOESCH, M. M. Conhecimento e sinergia como indutores da inovação regional em turismo: o caso do Observatório do Turismo no Distrito Federal (Brasil). Revista Brasileira de Pesquisa em Turismo, São Paulo, v. 11, n. 1, p. 19-38, 2017.

TORRES. Viva Torres: Parque Estadual da Guarita. Prefeitura Municipal de Torres, 2019. Disponível em: <https://torres.rs.gov.br/vivatorres/parque-daguarita/>. Acesso em: 4 jan. 2019.

UNESCO - United Nations Educational, Scientific and Cultural Organization. International Network of GEOPARKS. [s. I.] 2006. Disponível em $<$ http://www.unesco.org/science/earthsciences/geoparks/geoparks.htm>.

Acesso em: 2 dez. 2018.

UNESCO - United Nations Educational, Scientific and Cultural Organization. Geoparque Mundial Araripe (Brasil). Brasil, 2019. Disponível em: $<$ http://www.unesco.org/new/pt/brasilia/natural-sciences/environment/ biodiversity/geoparks/araripe-unesco-global-geopark/>. Acesso: 3 jan. 2019. 
UNESCO - United Nations Educational, Scientific and Cultural Organization. Guidelines and Criteria for National Geoparks seeking UNESCO's assistance to join the Global Geoparks Network (GGN). França, 2010, 12 p. Disponível em: <http://www.globalgeopark.org/uploadfiles/ 20129 6/ggn2010.pdf $>$. Acesso em: 20 dez. 2018.

UNESCO - United Nations Educational, Scientific and Cultural Organization. UNESCO Global Geoparks: celebrating earth heritage, sustaining local communities. França, 2016, 20 p. Disponível em: <https:/ lunesdoc.unesco.org/ark:/48223/pf0000243650>. Acesso em: 3 jan. 2019.

\section{Nota:}

trabalho apresentado no $30^{\circ}$ Encontro Nacional de Cursos de Graduação em Administração - ENANGRAD, realizado de 23 a 25 de agosto de 2019, Uberlândia, Minas Gerais, Brasil.

Israel Vasconselos Cardoso: Instituto Federal Catarinense Campus Santa Rosa do Sul, Santa Rosa do Sul, Santa Catarina, Brasil.

E-mail: israel.vasconselos@gmail.com

Link para o currículo Lattes: http://lattes.cnpq.br/0748121204229813

Joice Batista Felipe: Universidade do Extremo Sul Catarinense - UNESC, Criciúma, Santa Catarina, Brasil.

E-mail: joice@unesc.net

Link para o currículo Lattes: http://lattes.cnpq.br/4628540432930394

José Claudio Ramos Rodrigues: Instituto Federal Catarinense Campus Santa Rosa do Sul, Santa Rosa do Sul, Santa Catarina, Brasil.

E-mail: claudio_ramos@msn.com

Link para o currículo Lattes: http://lattes.cnpq.br/2218913355167544

Data de submissão: 24 de janeiro de 2020

Data de recebimento de correções: 05 de maio de 2021

Data do aceite: 05 de maio de 2021

Avaliado anonimamente 